\title{
The Impact of Type II DM on the Left Ventricular Function after Early Invasive Management in Middle Aged Patients with Non-St-Segment Elevation Myocardial Infarction \\ Mohsen Ali Mahmoud Salama, Kamal Ahmed Marghany, Amany Mohamed Seddik, Sherif Mohamed Ibrahim Halawa \\ Department of Cardiology, Faculty of Medicine, Al-Azhar University
}

\begin{abstract}
Background: Cardiovascular diseases are presently the leading causes of death in industrialized countries and expected to become so in emerging countries by 2020 . Among these, coronary artery disease (CAD) is the most prevalent manifestation and is associated with high mortality and morbidity.

Objective: The aim of this study was to assess the impact of Type II DM on the left ventricular function measured by 2D Speckle tracking Echocardiography in middle aged patients presenting with NSTEMI who will undergo PCI.

Patients and methods: This study was carried on sixty middle aged patients (according to WHO, it should be 55 years of age) admitted with NSTEMI who undergoing (PCI) during their admission at Al-Hussein University Hospital, Mostafa Kamel Military Hospital and the International Cardiac Center (ICC) at Alexandria. They divided into two equal groups (Diabetic group and Non-diabetic control group).

Results: The result showed that diabetes had a bigger effect on the initial systolic function but with early intervention. The difference in systolic function in both study groups was insignificant though it was a bit better in non-diabetics. Regarding to the site of significant LAD lesion, statistical difference was found in osteal LAD lesions (more in diabetics) and mid LAD lesions (more in non-diabetics).

Conclusion: Early intervention in diabetic patients lessens the effect of CAD on the myocardium even if the disease tends to be stronger than non-diabetics early on. The 2D speckle tracking echocardiography is a promising, feasible, and non-invasive modality to evaluate myocardial deformation.

Keywords: Type II DM, Left Ventricular Function, Early Invasive Management, Non-St-Segment Elevation Myocardial Infarction, CAD.
\end{abstract}

\section{INTRODUCTION}

Acute myocardial infarction (MI) is an area of coagulative necrosis of cardiac muscle due to prolonged ischemia. There are two subtypes of acute MI, STelevation MI (STEMI) and non-ST elevation MI (NSTEMI) ${ }^{(\mathbf{1})}$.

Atherosclerosis is the disease primarily responsible for most acute MI cases where $90 \%$ of them results from an acute thrombus that obstructs a coronary artery. Plaque rupture is considered to be the major trigger of coronary thrombosis, following plaque rupture, platelet activation and aggregation, coagulation pathway activation, and endothelial vasoconstriction occur and lead to coronary thrombosis and occlusion ${ }^{(2)}$.

Among patients presented with NSTEMI, 2 - 15 $\%$ show severe ongoing angina, profound or dynamic ECG changes, major arrhythmias, or haemodynamic instability upon admission or thereafter. Coronary angiography should be planned as soon as possible ${ }^{(3)}$.

Patients with type 2 diabetes mellitus (T2DM) have a higher risk of developing coronary artery disease (CAD) than do patients without T2DM. Additionally, $75 \%$ of $\mathrm{T} 2 \mathrm{DM}$ patients die as a consequence of cardiovascular diseases including CAD ${ }^{(4)}$.

In patients with T2DM, CAD tends to be a more complex disease characterized by small, diffuse, calcified, multivessel involvement [multivessel disease
(MVD) and often requires coronary revascularization in addition to optimal medical therapy to control angina ${ }^{(5)}$.

Adverse left ventricular (LV) remodelling begins in some patients with acute myocardial infarction (AMI) even after percutaneous coronary intervention (PCI), and according to previous studies, the incidence is around 30\%-35\% LV remodelling leads to heart failure and increases the risks for cardiovascular events and mortality ${ }^{(6)}$.

Left ventricular remodelling occurs in some patients of AMI with preserved EF even after PCI. The 2D speckle tracking echocardiography is a promising, feasible, and non-invasive modality to evaluate myocardial deformation ${ }^{(7)}$.

\section{AIM OF THE WORK \\ The aim of this study was to assess the impact of Type II DM on the left ventricular function measured by $2 \mathrm{D}$ Speckle tracking Echocardiography in middle aged patients presenting with NSTEMI who will undergo PCI.}

\section{PATIENTS AND METHODS}

This study was carried on sixty middle aged patients (according to WHO, it should be 55 years of age) admitted with NSTEMI who undergoing (PCI) during their admission at Al-Hussein University Hospital, 
Mostafa Kamel Military Hospital and the International Cardiac Center (ICC) at Alexandria.

Our patients were classified into two groups, diabetic patients (thirty patient) who were further subdivided into male diabetics (fifteen patients) and female diabetics (fifteen patients). The other group is the non-diabetic (control) group who were also subdivided into non diabetic males (fifteen patients) and nondiabetic females (fifteen patients). Our study was done in the period between December 2016 till February 2019.

Ethical approval and written informed consent: An approval of the study was obtained from AlAzhar University academic and ethical committee. Every patient signed an informed written consent for acceptance of the operation.

\section{Methods:}

All the patients were subjected to the following:

\section{Full history taking that included:}

\section{- Age}

- Gender

- Diabetes mellitus: Defined as having a $\mathrm{HbA1C}$ of $6.5 \%$ or greater on two occasions according to the American Diabetes Association or the use of blood glucose lowering medications (Insulin or oral drugs).

2. Clinical examination: Including general and local examination including blood pressure, pulse, respiratory rate and local examination of the heart and lung.

\section{Clinical assessment on admission:}

- Presence of typical chest pain (pressure-like retrosternal pain, occurring at rest or with minimal exertion).

- Blood pressure, presence of cardiogenic shock, level of consciousness and pulse.

\section{Standard 12 leads E.C.G}

- Includes pre-intervention and post-intervention to detect ischemic changes)

- Transient ST changes $(\geq 0.5 \mathrm{~mm}[0.05 \mathrm{mV}])$ during symptoms at rest strongly suggest ischemia and underlying severe CAD.

- ST depression (especially horizontal or down sloping) is highly suggestive of NSTE-ACS. Marked symmetrical precordial T-wave inversion ( $\geq 2 \mathrm{~mm}[0.2 \mathrm{mV}])$ suggests acute ischemia ${ }^{(8)}$.

\section{Admission laboratory data including:}

- Cardiac troponin, creatine kinase myocardial band $(\mathrm{CKmb})$ : Cardiac troponin is the cardiac biomarker of choice. Troponin is more specific and more sensitive than other biomarkers and becomes elevated relatively early in the disease process. Cardiac troponin may not be elevated within the first 2 to 4 hours after symptom onset, newer high sensitivity troponin assays have detectable elevations much earlier ${ }^{(9)}$.

- Blood urea, serum creatinine, serum uric acid.
Lipid profile (serum cholesterol, LDL, HDL and Triglycerides), HbA1c level, hemoglobin.

6. 2D Echocardiography according to the American Society of Echocardiography ${ }^{(\mathbf{1 0})}$.

- After stabilization (amelioration of chest pain), within the first 24 of the onset of chest pain and prior to coronary intervention, conventional echocardiographic Doppler study, as well as 2Dspeckle tracking imaging was performed for all patients using Phillips equipped with harmonic X5 variable frequency phase array transducer.

- Images were obtained with patients in the left lateral position at end-expiration according to the recommendations of the American Society of Echocardiography and connected to single12 lead ECG.

- All standard measurements were obtained in the parasternal long- and short-axis views; apical 4chamber, 2-chamber, and apical long axis views.

- Quantification of the LV dimensions was done.

- $\quad$ Study was carried at time of admission and after 6 weeks post revascularization. Ejection fraction, end diastolic dimensions, end systolic dimension, and fractional shortening was compared regarding all subgroups.

7. Speckle tracking 2D Echocardiography using global longitudinal strain around the timing of revascularization and 6 weeks post revascularization according to the American Society of Echocardiography ${ }^{(11)}$.

Assessment of ventricular regional wall motion abnormalities was done using a 16-segment model.13 Segmental wall motion was judged by an experienced cardiologist as normal 1, hypokinetic 2, akinetic 3 and dyskinetic 4. Wall motion score index (WMSI) represents the average value of analyzed segments.

Longitudinal strain imaging by 2D-speckle tracking echocardiography was done with high quality ECG gated images from the apical four-chamber, twochamber and three-chamber views, all were obtained at nearly identical heart rates.

The gain settings were optimized. The depth was reduced so that the $\mathrm{LV}$ occupied most of the image sector. Care was taken to avoid foreshortening of the $\mathrm{LV}$, the gray-scale frame-rate was kept between 50 and 90 frames/s; minimum three cardiac cycles were obtained for each loop.

All the images were obtained in breath-hold to avoid any breathing artifacts. All images were stored in cine-loop format. In order to measure the timing of cardiac events, LV inflow (mitral) and outflow (aortic) velocities were recorded using Pulsed wave Doppler.

Image analysis in the end-systolic frame, endocardial border was traced manually in its entirety, in the three apical views. The software then generated a region-of-interest (ROI) to include the entire myocardial thickness. The width of the ROI was 
manually adjusted as required. Care was taken to avoid including bright, echogenic pericardium in the ROI. The software then tracked the myocardial speckles frame-by frame and generates moving images displaying the tracking. Visual inspection of the moving image allowed the operator to determine the adequacy of the tracking. When the tracking was not accurate, the operator returned back and readjusted the ROI or an altogether new ROI was selected.

The software then divided the LV myocardium into six segments in each view and generates segmental and global longitudinal strain. As the myocardium usually shortened in longitudinal direction during systole, the longitudinal strain was displayed below the baseline. From these curves, peak systolic longitudinal stain was recorded for each of the myocardial segments.

The strain values for all the segments were recorded and averaged to obtain the global longitudinal strain (GLS), and, Bull's eye display of the regional and global longitudinal strain was generated.

GLS was defined to be reduced if it is less negative than -16 .

All echocardiographic and strain analyses were performed separately and blinded to other patient data.

\section{Angiographic and procedural details (pre- medications, use of stents, [TIMI] flow and complications:}

All patients underwent coronary angiography (Philips, IH5000) within 24 hours after being admitted to hospital with NSTE-MI (early invasive strategy), utilizing the retrograde, percutaneous transfemoral technique (Judkin's technique).

Philips cardiac cath. lab. System working with the most recent technology with latest Philips platform for the advanced intervention cardiac tool like unique dynamic coronary map feature and unique swing technique for diagnostic examination of coronary arteries with very low amount of contrast and radiation.

The angiographic studies included multiple selective injections for each coronary artery in at least two oblique projections, which recorded on digital camera at 30 frames/second ${ }^{(\mathbf{1 2})}$.

All selected cases will have the primary lesion in LAD with the absence of any other significant major vessel disease.

Coronary lesions were graded with respect to the degree of luminal narrowing. Calibers were used to grade the degree of obstruction, and changes were recorded according to a percent luminal narrowing.

Significant disease was arbitrarily determined to be $70 \%$ or greater luminal diameter narrowing. For the left main coronary artery (LM) $50 \%$ or greater stenosis was considered significant ${ }^{(\mathbf{1 3})}$.
Thrombolysis in Myocardial Infarction flow (TIMI flow) was noted, and acute occlusion was defined as TIMI flow 0 or 1 . Acute occlusions were differentiated from chronic total occlusions by angiographic appearance (thrombus, collaterals, and calcification), and by the ease with which a guide wire could be crossed.

PCI success was defined as achievement of vessel patency to a residual $>20 \%{ }^{(\mathbf{1 4})}$.

Follow up was at 6 weeks after the procedure by interviewing with the patients to determine the Left ventricular function after revascularization.

\section{Statistical analysis}

Recorded data were analyzed using the statistical package for social sciences, version 20.0 (SPSS Inc., Chicago, Illinois, USA). Quantitative data were expressed as mean \pm standard deviation (SD). Qualitative data were expressed as frequency and percentage.

\section{The following tests were done:}

- Independent-samples $t$-test of significance was used when comparing between two means.

- Chi-square $\left(\mathrm{x}^{2}\right)$ test of significance was used in order to compare proportions between two qualitative parameters.

- The confidence interval was set to $95 \%$ and the margin of error accepted was set to $5 \%$. The pvalue was considered significant as the following:

- Probability (P-value)

- P-value <0.05 was considered significant.

- P-value <0.001 was considered as highly significant.

- P-value >0.05 was considered insignificant.

\section{RESULTS}

Our patients were classified into two groups, diabetic patients (thirty patients) (Group I) who were further subdivided into male diabetics (fifteen patients) and female diabetics (fifteen patients). The other group (Group II) is the non-diabetic (control) group who were also subdivided into non-diabetic males (fifteen patients) and non-diabetic females (fifteen patients).

Regarding to age the mean age was 49.57 in diabetic group while it reached 51.27 among non-diabetic patients. There was statistically insignificant difference found between both groups according to age the $p$ value was 0.078 (statistically insignificant). Regarding BMI, it was 27.03 among diabetic group while it was 23.59 in Group II. There was statistically significant difference found between the two groups according to BMI the $p$ value was $<0.001$ (statistically significant) Table 1. 
Table (1): Comparison between the two studied groups according to demographic data

\begin{tabular}{|c|c|c|c|c|c|c|}
\hline & \multicolumn{2}{|c|}{ Diabetic $(n=30)$} & \multicolumn{2}{|c|}{ Non diabetic $(\mathrm{n}=\mathbf{3 0})$} & \multirow{2}{*}{ Test of Sig. } & \multirow{2}{*}{$\mathbf{p}$} \\
\hline & No. & $\%$ & No. & $\%$ & & \\
\hline Sex & & & & & \multirow{3}{*}{$\chi 2=0.0$} & \multirow{3}{*}{1.000} \\
\hline Male & 15 & 50.0 & 15 & 50.0 & & \\
\hline Female & 15 & 50.0 & 15 & 50.0 & & \\
\hline Age (years) & \multirow{4}{*}{\multicolumn{2}{|c|}{$\begin{array}{c}42.0-55.0 \\
49.57 \pm 3.78 \\
49.0(47.75-53.0)\end{array}$}} & \multirow{4}{*}{\multicolumn{2}{|c|}{$\begin{array}{c}39.0-55.0 \\
51.27 \pm 3.55 \\
52.0(50.0-54.0)\end{array}$}} & \multirow{4}{*}{$\mathrm{t}=1.794$} & \multirow{4}{*}{0.078} \\
\hline Min. - Max. & & & & & & \\
\hline Mean \pm SD & & & & & & \\
\hline Median (IQR) & & & & & & \\
\hline BMI $\left(\mathrm{kg} / \mathrm{m}^{2}\right)$ & \multirow{4}{*}{\multicolumn{2}{|c|}{$\begin{array}{c}20.0-34.0 \\
27.03 \pm 3.65 \\
27.60(24.0-29.20)\end{array}$}} & \multirow{4}{*}{\multicolumn{2}{|c|}{$\begin{array}{c}18.0-35.20 \\
23.59 \pm 3.29 \\
23.95(21.50-25.20)\end{array}$}} & \multirow{4}{*}{$\mathrm{t}=3.837 *$} & \multirow{4}{*}{$<0.001^{*}$} \\
\hline Min. - Max. & & & & & & \\
\hline Mean \pm SD. & & & & & & \\
\hline Median (IQR) & & & & & & \\
\hline
\end{tabular}

$\chi^{2}$ : Chi square test t: Student t-test

$\mathrm{p}$ : $\mathrm{p}$ value for comparing between the two studied groups, *: Statistically significant at $\mathrm{p} \leq 0.05$

Regarding to the ejection fraction within the first day of NSTEMI, the mean in group I was 43.77, while in group II was 46.57. This difference was statistically significant (P value 0.002). Regarding the ejection fraction six weeks after early intervention for NSTEMI, the mean in group I was 50.30, while in group II it was 51.23. This difference was statistically insignificant (P value 0.38 ).

The results showed that diabetes had a bigger effect on the initial ejection fraction but with early intervention. The difference in systolic function in both study groups was insignificant though it was better in non-diabetics Table 2.

Table (2): Comparison between the two studied groups according to ejection fraction

\begin{tabular}{|l|l|c|c|c|c|}
\hline & EF & Diabetic $(\mathbf{n}=\mathbf{3 0})$ & Non diabetic $(\mathbf{n}=\mathbf{3 0})$ & $\mathbf{t}$ & $\mathbf{p}$ \\
\hline \multirow{3}{*}{ Admission } & Min. - Max. & $36.0-49.0$ & $38.0-52.0$ & & \\
& Mean \pm SD. & $43.77 \pm 3.58$ & $46.57 \pm 3.27$ & $3.165^{*}$ & $0.002^{*}$ \\
& Median (IQR) & $43.50(41.50-47.0)$ & $47.0(44.75-49.0)$ & & \\
\hline & Min. - Max. & $42.0-59.0$ & $41.0-58.0$ & & \\
& Mean \pm SD. & $50.30 \pm 4.19$ & $51.23 \pm 3.97$ & 0.885 & 0.380 \\
After 6 & Median (IQR) & $50.0(49.0-53.25)$ & $51.0(49.0-54.25)$ & & \\
weeks & & $\mathbf{< 0 . 0 0 1}^{*}$ & $<\mathbf{0 . 0 0 1}^{*}$ & & \\
\hline
\end{tabular}

t: Student t-test , p: $p$ value for comparing between the two studied groups

$\mathrm{p}_{1}: \mathrm{p}$ value for Paired t-test for comparing between admission and after 6 weeks, $*$ : Statistically significant at $\mathrm{p} \leq 0.05$

Regarding the LVidD within the first day of NSTEMI, the mean in group I was 54.97, while in group II was 49.97. This difference was statistically significant ( $P$ value 0.008$)$.

Regarding the LVidD six weeks after early intervention for NSTEMI, the mean in group I was 52.27, while in group II it was 48.77, this difference was statistically significant (P value 0.034) Table 3. 
Table (3): Comparison between the two studied groups according to LVidD

\begin{tabular}{|c|c|c|c|c|}
\hline LVidD & Diabetic $(n=30)$ & Non diabetic $(\mathrm{n}=30)$ & $\mathrm{t}$ & $\mathrm{p}$ \\
\hline $\begin{array}{l}\text { Admission } \\
\text { Min. - Max. } \\
\text { Mean } \pm \text { SD. } \\
\text { Median (IQR) }\end{array}$ & $\begin{array}{c}41.0-67.0 \\
54.97 \pm 6.73 \\
55.0(49.75-60.25)\end{array}$ & $\begin{array}{c}40.0-65.0 \\
49.97 \pm 7.40 \\
48.0(43.0-56.25)\end{array}$ & $2.738 *$ & $0.008 *$ \\
\hline $\begin{array}{l}\text { After } 6 \text { weeks } \\
\text { Min. - Max. } \\
\text { Mean } \pm \text { SD. } \\
\text { Median (IQR) }\end{array}$ & $\begin{array}{c}41.0-64.0 \\
52.27 \pm 5.78 \\
52.0(48.0-56.25)\end{array}$ & $\begin{array}{c}41.0-64.0 \\
48.77 \pm 6.64 \\
47.0(42.75-54.25)\end{array}$ & $2.177 *$ & $0.034 *$ \\
\hline p1 & $<0.001^{*}$ & $0.001^{*}$ & & \\
\hline
\end{tabular}

t: Student t-test , p: $\mathrm{p}$ value for comparing between the two studied groups

$\mathrm{p}_{1}$ : $\mathrm{p}$ value for Paired t-test for comparing between admission and after 6 weeks.

As regards the LVidS within the first day of NSTEMI, the mean in group I was 42.47, while in group II it was 38.41 which was statistically significant (P value 0.017 ). Regarding the LVidS six weeks after early intervention for NSTEMI, the mean in group I was 37.63, while in group II it was 35.24. This difference was statistically insignificant (P value 0.132) Table 4.

Table (4): Comparison between the two studied groups according to LVidS

\begin{tabular}{|c|c|c|c|c|}
\hline LVidS & $\begin{array}{l}\text { Diabetic } \\
(\mathrm{n}=30)\end{array}$ & $\begin{array}{l}\text { Non diabetic } \\
\quad(\mathrm{n}=30)\end{array}$ & $\mathrm{t}$ & $\mathbf{p}$ \\
\hline $\begin{array}{l}\text { Admission } \\
\text { Min. - Max. } \\
\text { Mean } \pm \text { SD. } \\
\text { Median (IQR) }\end{array}$ & $\begin{array}{c}29.50-53.0 \\
42.47 \pm 6.32 \\
43.0(37.88-48.25)\end{array}$ & $\begin{array}{c}29.0-53.50 \\
38.41 \pm 6.43 \\
38.0(33.38-43.50)\end{array}$ & $2.465^{*}$ & $0.017^{*}$ \\
\hline $\begin{array}{l}\text { After } 6 \text { weeks } \\
\text { Min. - Max. } \\
\text { Mean } \pm \text { SD. } \\
\text { Median (IQR) }\end{array}$ & $\begin{array}{c}25.50-49.0 \\
37.63 \pm 6.03 \\
38.50(32.73-41.25)\end{array}$ & $\begin{array}{c}26.0-49.0 \\
35.24 \pm 6.07 \\
34.50(30.38-39.0)\end{array}$ & 1.528 & 0.132 \\
\hline $\mathrm{p} 1$ & $<0.001^{*}$ & $<0.001 *$ & & \\
\hline
\end{tabular}

\section{t: Student t-test}

$\mathrm{p}$ : $\mathrm{p}$ value for comparing between the two studied groups

$\mathrm{p}_{1}$ : $\mathrm{p}$ value for Paired t-test for comparing between admission and after 6 weeks

*: Statistically significant at $\mathrm{p} \leq 0.05$

Regarding the FS within the first day of NSTEMI, the mean in group I was 23.07, while in group II it was 23.95 which was statistically insignificant (P value 0.080 ). Regarding the FS six weeks after early intervention for NSTEMI, the mean in group I was 26.04, while in group II was 27.0. This difference was statistically insignificant (P value 0.287) Table 5. 
Table (5): Comparison between the two studied groups according to FS

\begin{tabular}{|l|c|c|l|l|}
\hline \multicolumn{1}{|c|}{ FS } & $\begin{array}{c}\text { Diabetic } \\
(\mathrm{n}=30)\end{array}$ & $\begin{array}{c}\text { Non diabetic } \\
(\mathrm{n}=30)\end{array}$ & $\mathrm{U}$ \\
\hline Admission & $18.0-27.60$ & $21.0-28.20$ & & \\
Min. - Max. & $23.07 \pm 1.95$ & $23.95 \pm 1.89$ & 332.0 & 0.080 \\
Mean \pm SD. & $23.0(22.0-24.0)$ & $23.80(22.88-24.75)$ & & \\
Median (IQR) & & & & \\
\hline After 6 weeks & $22.60-35.0$ & $22.50-35.40$ & \multirow{2}{*}{378.0} & 0.287 \\
Min. - Max. & $26.04 \pm 3.12$ & $27.0 \pm 3.66$ & & \\
Mean \pm SD. & $24.90(23.98-27.20)$ & $26.0(23.98-29.55)$ & & \\
Median (IQR) & $<0.001^{*}$ & $<0.001^{*}$ & & \\
\hline \multicolumn{1}{|c|}{ p1 } & &
\end{tabular}

A- U: Mann Whitney test

B- $p$ : $p$ value for comparing between the two studied groups

C- $\mathrm{p}_{1}$ : $\mathrm{p}$ value for Wilcoxon signed ranks test for comparing between admission and after 6 weeks

D- *: Statistically significant at $\mathrm{p} \leq 0.05$

Regarding to the diastolic dysfunction using (E/e') within the first day of NSTEMI, the mean in group I reached 10.45 , while in group II it was 10.31 . This difference was statistically insignificant (P value 0.906 ) Table 6.

Table (6): Comparison between the two studied groups according to different parameters

\begin{tabular}{|c|c|c|c|c|}
\hline & $\begin{array}{l}\text { Diabetic } \\
(\mathrm{n}=30)\end{array}$ & $\begin{array}{l}\text { Non diabetic } \\
(\mathrm{n}=30)\end{array}$ & Test of Sig. & $\mathrm{p}$ \\
\hline $\begin{array}{l}\text { E } \\
\text { Min. - Max. } \\
\text { Mean } \pm \text { SD. } \\
\text { Median (IQR) }\end{array}$ & $\begin{array}{c}0.34-0.97 \\
0.62 \pm 0.15 \\
0.59(0.53-0.69)\end{array}$ & $\begin{array}{c}0.32-1.03 \\
0.59 \pm 0.14 \\
0.61(0.48-0.65)\end{array}$ & $\begin{array}{c}\mathrm{U}= \\
407.50\end{array}$ & 0.529 \\
\hline $\begin{array}{l}\text { A } \\
\text { Min. - Max. } \\
\text { Mean } \pm \text { SD. } \\
\text { Median (IQR) }\end{array}$ & $\begin{array}{c}0.46-1.12 \\
0.75 \pm 0.21 \\
0.69(0.58-0.95)\end{array}$ & $\begin{array}{c}0.50-1.27 \\
0.77 \pm 0.18 \\
0.71(0.61-0.90)\end{array}$ & $\mathrm{t}=0.350$ & 0.728 \\
\hline $\begin{array}{l}\text { E/A } \\
\text { Min. - Max. } \\
\text { Mean } \pm \text { SD. } \\
\text { Median (IQR) }\end{array}$ & $\begin{array}{c}0.49-1.60 \\
0.85 \pm 0.32 \\
0.74(0.62-1.13) \\
\end{array}$ & $\begin{array}{c}0.50-1.15 \\
0.73 \pm 0.21 \\
0.65(0.59-0.85)\end{array}$ & $\begin{array}{c}U= \\
343.50\end{array}$ & 0.115 \\
\hline $\begin{array}{l}\text { Seotal e' } \\
\text { Min. - Max. } \\
\text { Mean } \pm \text { SD. } \\
\text { Median (IQR) }\end{array}$ & $\begin{array}{c}4.30-11.0 \\
6.66 \pm 1.93 \\
6.0(5.0-8.25)\end{array}$ & $\begin{array}{c}4.0-11.0 \\
6.40 \pm 1.90 \\
6.0(5.0-7.78)\end{array}$ & $\mathrm{U}=417.0$ & 0.618 \\
\hline $\begin{array}{l}\text { E/e' } \\
\text { Min. - Max. } \\
\text { Mean } \pm \text { SD. } \\
\text { Median (IQR) }\end{array}$ & $\begin{array}{c}6.50-16.0 \\
10.45 \pm 3.30 \\
8.75(7.50-14.25)\end{array}$ & $\begin{array}{c}6.50-16.0 \\
10.31 \pm 3.07 \\
9.0(8.0-14.0)\end{array}$ & $\mathrm{U}=442.0$ & 0.906 \\
\hline
\end{tabular}

t: Student t-test U: Mann Whitney test

$\mathrm{p}$ : $\mathrm{p}$ value for comparing between the two studied groups

Regarding the GLS within the first day of NSTEMI, the mean in group I was -11.45, while in group II it reached 12.92 which was statistically significant (P value 0.002 ). Regarding the GLS six weeks after early intervention for NSTEMI, the mean in group I was -13.10, while in group II it was 13.69.

This difference was statistically insignificant ( $\mathrm{P}$ value 0.180 ). The result showed that diabetes had a bigger effect on the initial systolic function but with early intervention and the difference in systolic function in both study groups was insignificant though it was a bit better in non-diabetics Table 7. 
Table (7): Comparison between the two studied groups according to GLS

\begin{tabular}{|l|c|c|c|c|}
\hline \multicolumn{1}{|c|}{ GLS } & Diabetic $(\mathrm{n}=30)$ & Non diabetic $(\mathrm{n}=30)$ & $\mathrm{U}$ & $\mathbf{p}$ \\
\hline Admission & & & & \\
Min. - Max. & $-14.0-10.90$ & $-14.90--10.50$ & & \\
Mean \pm SD. & $-11.45 \pm 4.32$ & $-12.92 \pm 0.98$ & $237.50^{*}$ & $0.002^{*}$ \\
Median (IQR) & $-12.30(-12.73--11.60)$ & $-13.15(-13.53--12.48)$ & & \\
\hline After 6 weeks & & & & \\
Min. - Max. & $-16.0-15.40$ & $-16.60-13.10$ & & \\
Mean \pm SD. & $-13.10 \pm 5.55$ & $-13.69 \pm 5.20$ & 359.50 & 0.180 \\
Median (IQR) & $-14.50(-14.95--13.13)$ & $-14.70(-15.53--13.85)$ & & \\
\hline \multicolumn{1}{|c|}{ p1 } & $<0.001 *$ & $<0.001 *$ & & \\
\hline
\end{tabular}

U: Mann Whitney test

$\mathrm{p}$ : $\mathrm{p}$ value for comparing between the two studied groups

$\mathrm{p}_{1}$ : $\mathrm{p}$ value for Wilcoxon signed ranks test for comparing between admission and after 6 weeks

*: Statistically significant at $\mathrm{p} \leq 0.05$

Regarding the site of significant LAD lesion, statistical difference was found in osteal LAD lesions (more in diabetics) and mid LAD lesions (more in non-diabetics) Table 8.

Table (8): Comparison between the two studied groups according to LAD lesion

\begin{tabular}{|l|c|c|c|c|l|l||}
\hline \multirow{2}{*}{ LAD lesion } & \multicolumn{2}{|c|}{$\begin{array}{c}\text { Diabetic } \\
(\mathbf{n = 3 0})\end{array}$} & \multicolumn{2}{c|}{$\begin{array}{c}\text { Non diabetic } \\
(\mathbf{n = 3 0})\end{array}$} & \multirow{2}{*}{$\square^{\square}$} & \multirow{2}{*}{${ }^{\mathbf{M C}} \mathbf{p}$} \\
\cline { 2 - 5 } & No. & $\mathbf{\%}$ & No. & \% & & \\
\hline Osteal & 5 & 16.7 & 2 & 6.7 & & \\
Proximal & 20 & 66.7 & 18 & 60.0 & & \\
Mid & 3 & 10.0 & 8 & 26.7 & 3.996 & \multirow{2}{*}{0.439} \\
Prox, mid & 1 & 3.3 & 1 & 3.3 & & \\
Distal & 1 & 3.3 & 1 & 3.3 & & \\
\hline
\end{tabular}

$\chi^{2}$ : Chi square test MC: Monte Carlo

$\mathrm{p}$ : $\mathrm{p}$ value for comparing between the two studied groups

As regards to the TIMI flow before PCI, significant statistical difference was found in TIMI 0 lesions (more in diabetics) who are those with total occlusions, otherwise there was no significant differences between both study groups Table 9.

Table (9): Comparison between the two studied groups according to TIMI flow

\begin{tabular}{|c|c|c|c|c|c|c|}
\hline \multirow[t]{2}{*}{ TIMI flow } & \multicolumn{2}{|c|}{$\begin{array}{c}\text { Diabetic } \\
(\mathbf{n}=\mathbf{3 0})\end{array}$} & \multicolumn{2}{|c|}{$\begin{array}{l}\text { Non diabetic } \\
\quad(n=30)\end{array}$} & \multirow[t]{2}{*}{$\square^{\square}$} & \multirow[t]{2}{*}{ p } \\
\hline & No. & $\%$ & No. & $\%$ & & \\
\hline Pre & & & & & & \\
\hline 0 & 3 & 10.0 & 0 & 0.0 & 3.158 & $\mathrm{FE}_{\mathrm{p}}=0.237$ \\
\hline I & 14 & 46.7 & 13 & 43.3 & 0.067 & 0.795 \\
\hline II & 13 & 43.3 & 17 & 56.7 & 1.067 & 0.302 \\
\hline III & 0 & 0.0 & 0 & 0.0 & - & - \\
\hline Post & & & & & & \\
\hline 0 & 0 & 0.0 & 0 & 0.0 & & \\
\hline I & 0 & 0.0 & 0 & 0.0 & & . \\
\hline II & 0 & 0.0 & 0 & 0.0 & - & - \\
\hline III & 30 & 100.0 & 30 & 100.0 & & \\
\hline
\end{tabular}

$\chi^{2}$ : Chi square test FE: Fisher Exact

$\mathrm{p}: \mathrm{p}$ value for comparing between the two studied groups 


\section{DISCUSSION}

Our patients were classified into two equal groups, diabetic patients (thirty patient) who were further subdivided into male diabetics (fifteen patients) and female diabetics (fifteen patients). The other group is the non-diabetic (control) group who were also subdivided into non-diabetic males (fifteen patients) and non-diabetic females (fifteen patients).

Many patients with diabetes have diastolic dysfunction ${ }^{(15)}$, that is the antecedent in the increasing prevalence of HF with preserved ejection fraction ${ }^{(16)}$. Similarly, systolic HF and coronary artery disease (CAD), including myocardial infarction (MI), are interlinked in a reciprocal relationship.

If LV remodeling does develop, it requires appropriate treatment (17), that includes revascularization and metabolically and hemodynamically effective treatment strategies that limit infarct size, cardiac dysfunction, and LV remodeling.

The aim of the current study was to assess the impact of Type II DM on the Left ventricular function measured by 2D Speckel tracking Echocardiography in middle aged patients presenting with NSTEMI who will undergo PCI.

The first finding of the current study was the significant statistical differences between EF in diabetic and non-diabetic patients on admission as the mean EF was $43.77 \pm 3.58$ and $46.57 \pm 3.27$ respectively. Nevertheless, after six weeks of admission there were no significant statistical differences between the two groups as regards to EF. The mean EF was $50.30 \pm 4.19$ and $51.23 \pm 3.97$ for diabetics and non-diabetics respectively.

This was in partial accordance to the study of Murcia et al. (18) which was randomized, doubleblind, placebo-controlled multicenter trial, evaluated the effect of diabetes on outcome of patients with NSTEMI. They found that on admission the mean EF was $31.2 \pm 6.7$ and $30.5 \pm 6.9$ for diabetics and nondiabetics respectively. While after 2 months of admission the mean EF was $41.5 \pm 7.0$ and $42.0 \pm 6.8$ respectively. No significant statistical differences in $\mathrm{EF}$ were found by them either on admission or on follow up. It should be noted that the main difference between that study and the present study was that most of their patients had systolic impairment.

The study of Savage et al. ${ }^{\left({ }^{(9)}\right)}$ also agreed to the current results regarding the insignificant statistical differences in EF between diabetics and non-diabetics after NSTEMI. They found that on admission, the mean $\mathrm{EF}$ was $47 \pm 6.0$ and $45.8 \pm 8.6$ for diabetics and non-diabetics respectively, while after 1 month follow up the mean EF was $56.8 \pm 7.18$ and $57.0 \pm 4.15$ respectively. They found no significant differences between the two groups regarding EF neither on admission nor after 1 month follow up.
In contrary to the present study, the study of Jafe et al. (20) who found diabetic patients had significantly lower EF than non-diabetic patients 4 weeks of follow up after acute MI $(36.8 \pm 11.2 \mathrm{VS}$ $45.0 \pm 13.1$ respectively). Their conclusion was that diabetes significantly affect ventricular remodeling after acute MI.

The current results also showed that there was significant difference in TIMI flow 0 in diabetics than non-diabetics but there were no significant statistical differences between diabetics and non-diabetics as regards to TIMI II-III flow.

The study of Prasad $\boldsymbol{e t}$ al. ${ }^{(21)}$ investigated the impact of diabetes mellitus on myocardial perfusion after primary percutaneous coronary intervention (PCI) utilizing myocardial blush grade. They matched our results regarding TIMI flow as they found were no differences between those with or without diabetes with regard to postprocedural Thrombolysis In Myocardial Infarction flow grade 3 (>95\%), distribution of infarct-related artery, and the frequency of stent deployment .

As regards to Killip class, our results showed that patient with class 4 were more likely to be diabetic with the presence of significant statistical difference regarding Killip class IV patients, otherwise, there were no significant differences between diabetics and non-diabetics.

The results of Abid et al. ${ }^{(22)}$ was partially consistent with our results as they found that diabetic patients presented in more advanced Killip class as $32(26.7 \%)$ patients presented in Killip class II, $13(10.8 \%)$ patients presented in Killip class III and $6(5 \%)$ patients presented in Killip class IV. In the nondiabetic group, 68(20.7\%), 24(7.3\%) and 11(3.4\%) patients presented in these Killip classes respectively.

The results of Wei et al. ${ }^{(23)}$ was consistent with the current results. They reported that compared with the non-DM group, the DM patients had significantly higher Killip class grade (III/IV).

The current results showed that diabetic patients had slightly higher mean Grace score than nondiabetic patients but without any significant statistical differences $(117.73 \pm 26.37$ VS $107.10 \pm 16.57$ respectively).

The recent study of Quinglan et al. (24) mismatched our results as they found diabetic patients had significantly higher grace score than non-diabetic patients.

The recent study of Mengge $\boldsymbol{e t}$ al. ${ }^{(25)}$ also found significantly higher grace score in diabetic patients than non-diabetic patients which was in contrary to our results.

With respect to LvidD, the current results showed border line significant differences between diabetics and non-diabetics in admission and after 6 weeks follow up, while as regards to Lvids, the results 
showed border line significance on admission only 3 . and $\mathrm{n}$ significant difference after 6 weeks follow up.

The study of Stone et al. ${ }^{(26)}$ partially matched our results as they found no significant differences 4 . between diabetics and non-diabetics as regards to LvidD and LvidS neither on admission nor after 4 months follow up.

The results of the study conducted by Granger et al. ${ }^{(27)}$ were also in partial accordance with our 5 . results. Their results showed border line significant statistical differences between diabetic and nondiabetics as regards to LvidD on admission and after follow up, while according to LvidS, they found no significant differences at all between the two patientk. categories.

In the present study, the mean $\mathrm{n}$ admission FS was $23.07 \pm 1.95$ and $23.95 \pm 1.89$ in diabetics and. non-diabetics respectively while after 6 weeks the mean FS was $26.04 \pm 3.12$ and $27.0 \pm 3.66$ respectively. Accordingly, there were no significant. statistical differences between diabetics and nondiabetics as regards to FS.

The previously mentioned study of Kuliczkowski et al. ${ }^{(28)}$ completely matched our results as they found no significant statistical differences between diabetics and non-diabetics as regards to FS neither on admission or on follow up. Nevertheless, the study of Jaffe et al found significant statistical differences between the two groups of patients as regards to FS on admission but not after follow up.

As regards to GLS, the mean admission measurements were was $-11.45 \pm 4.32$ and $-12.92 \pm$ 0.98 for diabetics and non-diabetics respectively while the mean score on follow up was $-13.10 \pm 5.55$ and $13.69 \pm 5.20$ respectively. Despite the significant statistical differences on admission, there were no significant differences on follow up.

The study conducted by Hoogslag et al. (29) aimed at comparing GLS after st segment elevation myocardial infarction with LAD culprit vessel in patients with diabetes versus without diabetes mellitus.

\section{CONCLUSION}

1. Patients with type 2 diabetes mellitus (T2DM) had a higher risk of developing coronary artery disease (CAD) than patients without T2DM. Additionally, $75 \%$ of T2DM patients died as a consequence of cardiovascular diseases including CAD.

2. In patients with $\mathrm{T} 2 \mathrm{DM}, \mathrm{CAD}$ tends to be a more complex disease characterized by small, diffuse, calcified, multivessel involvement [multivessel disease (MVD) and often requires coronary revascularization in addition to optimal medical therapy.
Early intervention in diabetic patients lessens the effect of CAD on the myocardium even if the disease tends to be stronger than non-diabetics early on.

Adverse left ventricular (LV) remodelling begins in some patients with acute myocardial infarction (AMI) even after percutaneous coronary intervention (PCI), remodelling leads to heart failure and increases the risks for cardiovascular events and mortality.

The 2D speckle tracking echocardiography is a promising, feasible, and non-invasive modality to evaluate myocardial deformation.

\section{RECOMMENDATIONS}

$\mathrm{DM}$ is a major risk factor for CAD so it should be controlled thoroughly to prevent early progress of premature coronary artery disease.

Early intervention is very important in the prognosis of NSTEMI diabetic and non-diabetic patients whose lifestyle and daily activity will be totally different.

Speckle tracking Echocardiography is a more accurate tool for follow up of LV function and recovery than 2D transthoracic Echocardiography.

\section{REFERENCES}

1. Baroldi G (2001): Different types of myocardial necrosis in coronary heart disease: a pathophysiologic review of their functional significance. Am Heart J., 89: 801-11.

2. Davies MJ, Thomas AC (2004): Plaque fissuring: the cause of acute myocardial infarction, sudden ischemic death, and crescendo angina. Br Heart J., 53: 363-73.

3. Yan AT, Yan RT, Tan M et al. (2006): ST-segment depression in non-ST elevation acute coronary syndromes: quantitative analysis may not provide incremental prognostic value beyond comprehensive risk stratification. Am Heart J., 152:270-27.

4. Bassand JP, Hamm CW, Ardissino D et al. (2007): Guidelines for the diagnosis and treatment of non-STsegment elevation acute coronary syndromes. Eur Heart J., 28: 159-63.

5. Cavallini C, Savonitto S, Violini R et al. (2005): Impact of the elevation of biochemical markers of myocardial damage on long-term mortality after percutaneous coronary intervention: PCI study. Eur Heart J., 26: 149:58.

6. Savoye C, Equine O, Tricot O et al. (2006): Left ventricular remodelling after anterior wall acute myocardial infarction in modern clinical practice (from the REmodelage VEntriculaire [REVE] study group). Am J Cardiol., 98(9):1144-9.

7. Pfeffer MA, Braunwald (1990):. Ventricular remodelling after myocardial infarction. Experimental observations and clinical implications. Circulation, 81(4):1161-72.

8. Rouan GW, Lee TH, Cook EF et al. (1989): Clinical characteristics and outcome of acute myocardial infarction in patients with initially normal or nonspecific electrocardiograms (a report from the 
Multicenter Chest Pain Study). Am J Cardiol., 64:1087-1092.

9. Eggers KM, Jaffe AS, Venge $P$ et al. (2011): Clinical implications of the change of cardiac troponin I levels in patients with acute chest pain - an evaluation with respect to the Universal Definition of Myocardial Infarction. Clin Chim Acta., 412:91-97.

10. D'Andrea A, Cocchia R, Caso $P$ et al. (2011): Global longitudinal speckle-tracking strain is predictive of left ventricular remodelling after coronary angioplasty in patients with recent non-ST elevation myocardial infarction. Int J Cardiol., 153:185-91.

11. Nicolosi GL, Golcea S, Ceconi C et al. (2009): Effects of perindopril on cardiac remodelling and prognostic value of pre-discharge quantitative echocardiographic parameters in elderly patients after acute myocardial infarction: the PREAMI echo substudy. Eur Heart J., 30(13):1656-65.

12. Krishnaswami S, Joseph G, Punnoose E et al. (1996): Coronary angiographic findings in patients with diabetes: an exercise in cardiovascular epidemiology. The Journal of the Association of Physicians of India, 44(3):169-71.

13. Miranda CP, Liu J, Kadar A et al. (1992): Usefulness of exercise-induced ST-segment depression in the inferior leads during exercise testing. Am J Cardiol., 69(4):303-7.

14. Simonton CA, Leon MB, Baim DS et al. (1998): Optimal' directional coronary atherectomy: final results of the Optimal Atherectomy Restenosis Study (OARS). Circulation, 97:332-9.

15. Redfield MM, Jacobsen SJ, Burnett JC et al. (2013): Burden of systolic and diastolic ventricular dysfunction in the community-appreciating the scope of the heart failure epidemic. JAMA., 289:194202.

16. Borlaug BA, Paulus WJ (2017): Heart failure with preserved ejection fraction: pathophysiology, diagnosis and treatment. Eur Heart J., 32:670-9.

17. Landmesser U, Wollert KC, Drexler H (2018): Potential novel pharmacological therapies for myocardial remodeling. Cardiovasc Res., 81:519-27.

18. Murcia AM, Hennekens CH, Lamas GA et al. (2014): Impact of diabetes on mortality in patients with myocardial infarction and left ventricular dysfunction. Arch Intern Med., 164(20):2273-9.

19. Savage MP, Krolewski AS, Kenien GG et al. (2008): Acute myocardial infarction in diabetes mellitus and significance of congestive heart failure as a prognostic factor. Am J Cardiol., 62:665-669.

20. Jaffe AS, Spadaro JJ, Schechtman K et al. (2012): Increased congestive heart failure after myocardial infarction of modest extent in diabetes mellitus patients. Am Heart J., 108:31-37.

21. Prasad A, Stone GW, Stuckey TD et al. (2005): Impact of diabetes mellitus on myocardial perfusion after primary angioplasty in patients with acute myocardial infarction. J Am Coll Cardiol., 45(4):50814.

22. Abid AR, Mallick NH, Shahbaz A et al. (2015): Inhospital outcome of acute myocardial infarction (st segment elevation type) in diabetics and nondiabetics. J Coll Physicians Surg Pak., 15(9):524-7.

23. Wei CC, Shyu KG, Cheng JJ et al. (2016): Diabetes and Adverse Cardiovascular Outcomes in Patients with Acute Coronary Syndrome - Data from Taiwan's Acute Coronary Syndrome Full Spectrum Data Registry. Acta Cardiol Sin., 32(1):31-38.

24. Qinglan D, Marjorie F, Erica S et al. (2019): Association of Diabetes Mellitus With Health Status Outcomes in Young Women and Men After Acute Myocardial Infarction: Results From the VIRGO Study. Journal of the American Heart Association, 8(17):10988.

25. Mengge ZJL, Yongchen HJ, Yong $\mathrm{H}$ et al. (2018): Prevalence and in-hospital outcomes of diabetes among patients with acute coronary syndrome in China: findings from the Improving Care for Cardiovascular Disease in China-Acute Coronary Syndrome Project. Cardiovasc. Diabetol., 17:147-52.

26. Stone PH, Muller JE, Hartwell T et al. (2009): MILIS Study Group.The effect of diabetes mellitus on prognosis and serial left ventricular function after acute myocardial infarction: contribution of both coronary disease and diastolic left ventricular dysfunction to the adverse prognosis. J Am Coll Cardiol., 14:49-57

27. Granger CB, Califf RM, Young S et al. (2013): Thrombolysis and Angioplasty in Myocardial Infarction (TAMI) Study Group. Outcome of patients with diabetes mellitus and acute myocardial infarction treated with thrombolytic agents. Jam Coll Cardiol., 21:920-925.

28. Kuliczkowski W, Miszalski-Jamka K, Kaczmarski J et al. (2017): No-reflow and platelet reactivity in diabetic patients with ST-segment elevation myocardial infarction. Postepy Kardiol Interwencyjnej., 13(4):326-330.

29. Hoogslag GE, Abou R, Joyce $\mathrm{E}$ et al. (2015):Comparison of Changes in Global Longitudinal Peak Systolic Strain After ST-Segment Elevation Myocardial Infarction in Patients With Versus Without Diabetes Mellitus. Am J Cardiol., 116(9):1334-9. 